\title{
Stochastic model of project implementation of the new generation ecological materials - sulfur polymers in key branches of the economy
}

\author{
Iurii Androsiuk ${ }^{1}$, Oksana Zhylinska ${ }^{2}$, and Valeriy Balan ${ }^{2, *}$ \\ ${ }^{1}$ West-East Consulting, 34 Khreshchatyk str., 01001 Kyiv, Ukraine \\ ${ }^{2}$ Taras Shevchenko National University of Kyiv, 64/13, Volodymyrska Street, Kyiv, 01601 Ukraine
}

\begin{abstract}
In the article, the authors propose a stochastic model for the implementation of the project for the introduction of sulfur polymers in key sectors of the Ukrainian economy. A model based on GERT networks and the theory of closed flow graphs allow you to clearly and fully represent the stages, take into account the stochastic nature of both the development process itself (through the use of probabilistic considerations regarding the time of each operation and the reliability of its execution), and the influence of various factors of endo- and exogenous in nature. The project provides for the development and application of ecological polymer composite materials (sulfur asphalt concrete and sulfur concrete) with the introduction of industrial waste, including sulfur-containing ones, to ensure the principles of a circular economy. According to the authors, the project is one of the conditions for stimulating the implementation of strategic directions for the development of the domestic industry on the use of the latest environmental technologies of sulfur polymer materials in the construction of the country's infrastructure, providing for a reduction in the ecological, carbon, sulfur-containing and material footprint, the transition to environmentally friendly technological solutions, the introduction of principles of circularity of the economy.
\end{abstract}

\section{Introduction}

One of the priority tasks requiring extraordinary attention not only in Ukraine but also in other countries is the solution of the environmental, technical and economic problem arising from the utilization of sulfur and is formed as a by-product of oil and gas processing, the volume of which reaches several tens of millions of tons. Sulfur compounds in terms of their negative impact on the environment occupy one of the first places among pollutants. Converting this sulfur and man-made waste from storage facilities into promising building materials is an important national task, which is in line with the goals of the European Green Deal [1], which soon will form the main trends in climatic, environmental, economic, transport, agricultural policies not only in the EU but also in other European countries, in particular, Ukraine (Low of Ukraine, 2019 [2], Order of the Cabinet of Ministers of Ukraine, 2017 [3], Order of the Cabinet of Ministers of Ukraine,

\footnotetext{
${ }^{*}$ Corresponding author: balan_v_g@ukr.net
} 
2019 [4], [5], [6]). Note that the European Green Deal, adopted in 2019, is a policy document that defines strategic changes in the EU's environmental and climate policy; it is an ambitious program describing the transition to a climate-neutral, circular economy by 2050 - an extremely complex and ambitious step that should completely change the economies of the European Union and partner countries [7]. Specific policies and measures foreseen by the European Green Deal include the development of several strategies, in particular an industrial strategy and an action plan for a circular economy (in particular waste management), reforms in the construction industry, a chemical strategy, etc. [8].

Considering the above, the involvement of Ukraine in the process of creating a climateneutral Europe is a prerequisite. Currently, the formation of a conceptual and value basis for foreign policy cooperation on these issues has begun, in particular, within the framework of the Eastern Partnership, the deepening of the process of association with the EU, the Paris Agreement, environmental conventions, the Energy Community, the Memorandum of strategic energy partnership between Ukraine and the EU, etc.

The study of innovative waste management systems introduced in the world, as well as the ways and algorithms for their implementation, showed that the only economically, environmentally and socially effective strategic way of waste management in Ukraine is the introduction of a waste management system, the ultimate goal of which will be to obtain secondary material and/or energy raw materials, that is, an innovative system for managing material and energy cyclically closed flows-raw materials, materials, products, waste, secondary raw materials [3].

Thus, today there is a question of ensuring the use of resource-saving, environmental and durable materials in the construction of infrastructure to reduce turnaround times, reduce costs, energy costs and the use of by-products and waste. Against the background of the deteriorating environmental situation and the active restructuring of the Ukrainian economy to the Western model, the construction and infrastructure spheres of our state need new, better materials. These materials should have better performance properties, a high level of environmental friendliness and greater availability at the price of the finished product. Sulfur asphalt concrete and sulfur concrete (sulfur polymers) have significantly better operational properties and strength characteristics in comparison with classical materials - bituminous asphalt concrete and cement concrete.

\section{Methods}

Based on the foregoing, a project is proposed for the introduction of sulfur polymers in key sectors of the Ukrainian economy (supported by the Ministry of Environmental Protection and Natural Resources of Ukraine, the Ministry of Infrastructure of Ukraine), the main stages of implementation of which in the form of a stochastic model are given in fig. 1. To improve the efficiency of the implementation of this project, it is advisable to use stochastic models based on GERT (Graphical Evaluation Review Technique)-networks, $W$-functions and the theory of closed flow graphs [9]. Examples of the application of these models for solving various problems of project management are given in the works: [10] - for the implementation of the methodology for the analysis of strategic gaps in the strategic management of the organizational development of the enterprise, [11] - for the formation of competitive strategies of the milk processing company, [12] - for the project of choice and implementation of an enterprise management information system, [13] - to form a mechanism for the commercialization of intellectual property, [14] - for analysis of concurrent new product development processes.

The choice of this tool for modelling the implementation process of the project is due to the fact that GERT-grids allow: 
1) clearly and fairly fully present all stages of the implementation process of the project for the introduction of sulfur polymers in key sectors of the Ukrainian economy;

2) take into account the stochastic nature of both the development process itself (through the use of probabilistic considerations regarding the time of each operation and the reliability of its execution), and the influence of various endo- and exogenous factors;

3 ) take into account as much as possible possible changes in various macro- and microfactors of influence on the process of project implementation;

4) determine in advance possible problematic and "bottlenecks" of this process and identify the main risks associated with the implementation of the project and its individual stages;

5) assess the duration of individual stages of the implementation process of the project for the introduction of sulfur polymers in key sectors of the Ukrainian economy and the entire process as a whole;

6) determine the probabilities of completing individual stages and obtaining results in the process of implementing this project;

7) to balance the activities of responsible persons in the process of implementing the project for the introduction of sulfur polymers in key sectors of the Ukrainian economy and to increase the effectiveness of the existing measures both in terms of their validity and in terms of future implementation.

\section{Results and discussion}

In fig. 1 shows a generalized GERT-grid for the implementation of the project of introducing sulfur polymers in key sectors of the economy, built taking into account the reduction of sequential and parallel arcs and loops (Phillips et al., 1981) of the original model (due to its cumbersome nature, it is not presented in the article).

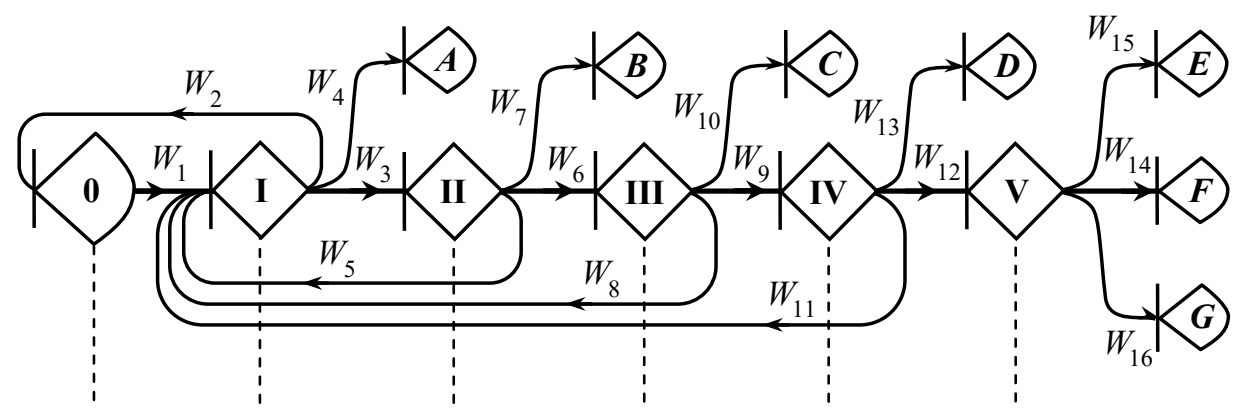

Fig. 1. Generalized stochastic model of the implementation of the project for the introduction of sulfur polymers in key sectors of the Ukrainian economy.

According to [9] $W(s)=p \cdot M(s)$, where $p$ - the probability of realization of the corresponding arc (operation) of the grid, $M(s)$ - creative function of moments. Note that in the degenerate case $M(s)=\exp (s d)$ ( $d$-duration of the operation), and in the case of normal distribution $M(s)=\exp \left(s m+0,5 s^{2} \sigma^{2}\right) \quad(m-$ the expected duration of the operation, $\sigma$ - standard deviation).

Let's consider in more detail the content of the stages of the project.

Stage 1. Development and approval of regulatory, organizational and technical conditions for the beginning of the formation of the sulfur-polymer direction of the Ukrainian industry, including the preparation of scientific justifications, proposals for the implementation of relevant infrastructure projects $\left(W_{l}\right)$. 
The implementation of the 1st stage of the project provides for:

1) creation of an experimental installation (industrial and laboratory equipment) for the production of sulfur polymers (sulfur asphalt concrete, sulfur concrete, sulfuric binder) using zero emission technology, certification of this equipment;

2) obtaining certification of sulfur asphalt concrete in cooperation with Ukravtodor and the State Department of Scientific Research Institute for their use in the construction of roads, infrastructure projects, and the like;

3) obtaining certification of sulfur concrete and products made from them in cooperation with the Ministry of Regional Development, Construction and Housing and Communal Services of Ukraine;

4) obtaining certification of sulfur polymers for their use in industrial projects of NJSC Naftogaz of Ukraine and State Enterprise Ukroboronprom;

5) support of applied research and experimental development aimed at creating competitive advantages in the use of sulfur polymer materials in the Ukrainian industry;

6) creation of a project office;

7) creation of a computer engineering center.

Stage 2. Determination of key directions for the use of sulfur polymer materials in the Ukrainian industry and implementation of pilot projects, including the development of mechanisms of state support and financial and economic justifications for these projects $\left(W_{3}\right)$.

At the 2nd stage, the following activities are planned:

1) preparation and implementation, together with Ukravtodor, of a pilot project for the development of road infrastructure for the use of sulfur concrete within the framework of the Eastern Partnership initiative;

2) creation of an industrial (techno, scientific) park for the use of sulfur polymer technologies in the Mykolaiv (Odessa, Kherson) region in the development of port infrastructure following the requirements of the European Green Deal concept and Sustainable and Smart Mobility Strategy [15];

3 ) the creation of an industrial (techno, scientific) park for the use of sulfur concrete for the implementation of projects for the development of road infrastructure, in particular for the implementation of projects for the development of international cross-border transport routes (towards the borders with Romania, Hungary, Moldova and Poland) as part of the development of the trans-European transport network TEN-T;

4) creation of an industrial (techno, scientific) park for the production of ecological polymer composite materials (building, road construction, etc.) using industrial waste, including sulfur-containing waste, to ensure the principles of a circular economy and ensure compliance with the European Green Deal concept (Paris Agreement);

5) implementation of pilot projects using sulfur polymers for the industry needs of NJSC Naftogaz of Ukraine and State Enterprise Ukroboronprom;

6) establishment of serial production of a line of equipment for the production of sulfur polymers (Nano-Liner) (zero emission technology by the concept of the European Green Deal);

7) introduction of training programs for training highly qualified specialists for Ukrainian enterprises in educational institutions of I-IV levels of accreditation.

Stage 3. Ensuring coordinated activities of state and scientific bodies, business structures and financial organizations in the organization of high-tech production of sulfur polymer materials, the formation and maintenance of a single system for their manufacture and use in the Ukrainian industry and scientific and technical support for the implementation of relevant infrastructure projects $\left(W_{6}\right)$.

Stage 3 is aimed at: 
1) carrying out applied scientific research and the beginning of regular pilot production of sulfur polymers and products from them (creation of enterprises) with the provision of new jobs for technical workers, engineers, managers and scientists;

2) ensuring sustainable development of education, training, professional retraining and advanced training of specialists in the system of using broad polymer materials in production;

3) creation of a separate certification centre sulfur polymer;

4) widespread introduction of the use of sulfur polymers in the implementation of infrastructure projects in Ukraine within the framework of the Eastern Partnership initiative and the creation of a trans-European transport network TEN-T with minimization of $\mathrm{CO}_{2}$ emissions, in particular:

- construction and repair of the infrastructure of seaports;

- construction and repair of the infrastructure of river ports;

- construction of treatment facilities using sulfur polymers, structures in contact with aggressive media.

Stage 4. Creation of a modern innovative direction for the production of sulfur polymer materials and increasing its energy efficiency, rational use of resources, commissioning of energy resource platforms $\left(W_{9}\right)$.

At the 4th stage, it is planned to work in the following areas:

1) researching the impact of aggressive environments of the Black Sea on classical and sulfur polymeric building materials to use them as efficiently as possible in the implementation of projects in the Black Sea region;

2) development and implementation of energy resource platforms with the widespread use of sulfur polymers;

3) the beginning of the formation of a promising segment of production: the creation of platforms for the extraction and processing of hydrogen sulfide for "green hydrogen" and sulfur (sulfur polymers, fertilizers, etc.).

Stage 5. Implementation of the regular functioning of an integrated system for the use of sulfur polymer materials in the circular economy of Ukraine $\left(W_{12}\right)$.

The 5th stage should provide:

1) the functioning of a closed cycle for the production of sulfur polymer materials, including the creation of a sustainable innovative and high-tech industry using sulfur polymer materials, fully complies with the requirements of the circular economy and the concept of the European Green Deal;

2) entering international markets, the beginning of the serial production of equipment and polymer materials, including the export of finished products abroad (industrial equipment and Nano-Liner factories, various types of urgent binder)

3) participation in large-scale international projects (energy resource platforms of the countries of the Black Sea region, international highways), integration of the Ukrainian research sector and practical implementation of projects using sulfur polymer materials in the global world innovation environment. Note that in the constructed grid model (Fig. 1) the following notations are given:

$W_{2}, W_{5}, W_{8}, W_{11}$ - making decisions on improving certain operations of the relevant stages of the project if necessary (appearance of relevant information, changes, revision of the content of works, etc.);

$W_{4}, W_{7}, W_{10}, W_{13}$ - deciding to leave the project after the relevant stage;

$W 1_{4}, W_{15}, W_{16}$ - work on the overall completion of the project following the optimistic, pessimistic and most likely scenarios.

To determine the parameters of the stochastic model, one can use the grid reduction rules, represented as a closed current graph (Fig. 2), and write a topological equation 
(Mason's equation) for each of the resulting closed graphs, which in the general case has the following form [9]:

$$
1-\sum_{i} W\left(L_{i}(1)\right)+\sum_{j} W\left(L_{j}(2)\right)+\ldots+(-1)^{m} \sum_{p} W\left(L_{p}(m)\right)=0
$$

where $\sum_{i} W\left(L_{i}(k)\right)$ - sum of $W$-functions of all loops $k$-order in a closed graph.

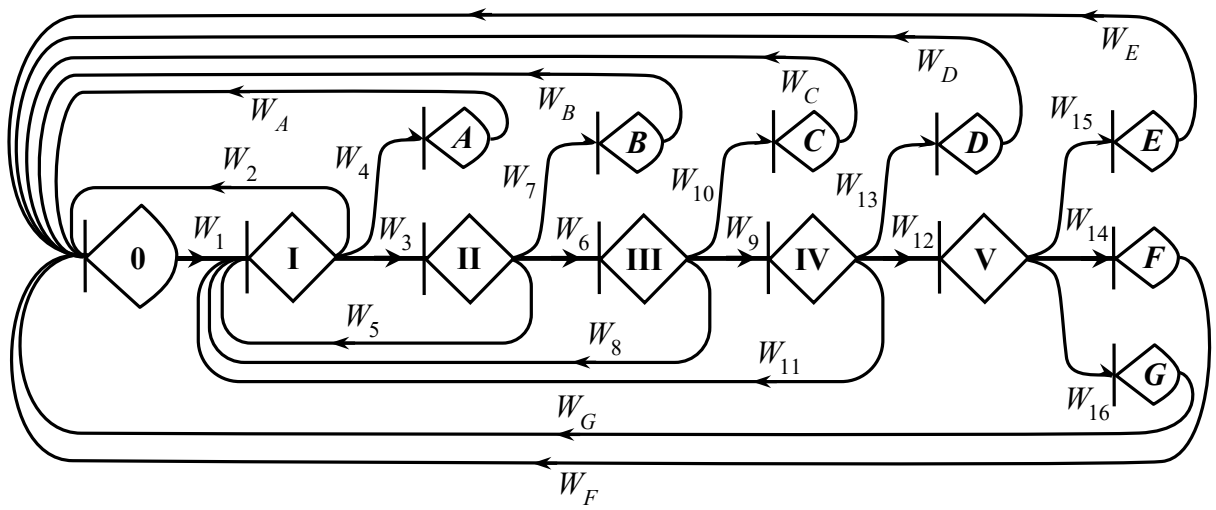

Fig. 2. Closed generalized stochastic model of the process of introducing the concept of sulfur polymers into key sectors of the Ukrainian economy.

Mason's equations for the closed flow graph of the developed model will look like (2) (8):

$$
\text { for node } A: 1-W_{1} W_{2}-W_{1} W_{4} W_{A}=0 \text {; }
$$

for node $B: 1-W_{1} W_{2}-W_{3} W_{5}-W_{1} W_{3} W_{7} W_{B}=0$;

for node $C: 1-W_{1} W_{2}-W_{3} W_{5}-W_{3} W_{6} W_{8}-W_{1} W_{3} W_{6} W_{10} W_{C}=0$;

for node $D: 1-W_{1} W_{2}-W_{3} W_{5}-W_{3} W_{6} W_{8}-W_{3} W_{6} W_{9} W_{11}-W_{1} W_{3} W_{6} W_{9} W_{13} W_{D}=0$;

for node $E: 1-W_{1} W_{2}-W_{3} W_{5}-W_{3} W_{6} W_{8}-W_{3} W_{6} W_{9} W_{11}-W_{1} W_{3} W_{6} W_{9} W_{12} W_{15} W_{E}=0$;

for node $F: 1-W_{1} W_{2}-W_{3} W_{5}-W_{3} W_{6} W_{8}-W_{3} W_{6} W_{9} W_{11}-W_{1} W_{3} W_{6} W_{9} W_{12} W_{14} W_{F}=0$;

for node $G: 1-W_{1} W_{2}-W_{3} W_{5}-W_{3} W_{6} W_{8}-W_{3} W_{6} W_{9} W_{11}-W_{1} W_{3} W_{6} W_{9} W_{12} W_{16} W_{G}=0$.

According to the conclusions of the theory of closed flow graphs in the Mason equation (for example, for node $\mathrm{F}$ ) it is necessary to replace $W_{F}$ on $1 / W_{F}^{E}$, де $W_{F}^{E}-W$-function of the corresponding closed flow graph with node termination $\mathrm{F}$. Therefore, from topological equations (2) - (8) it can obtain expressions (9) - (15) for equivalent $-\mathrm{W}$-functions of the grid for each of its nodes.

$$
W_{A}^{E}=\frac{W_{1} W_{4}}{1-W_{1} W_{2}} ;
$$




$$
\begin{gathered}
W_{B}^{E}=\frac{W_{1} W_{3} W_{7}}{1-W_{1} W_{2}-W_{3} W_{5}} ; \\
W_{C}^{E}=\frac{W_{1} W_{3} W_{6} W_{10}}{1-W_{1} W_{2}-W_{3} W_{5}-W_{3} W_{6} W_{8}} ; \\
W_{D}^{E}=\frac{W_{1} W_{3} W_{6} W_{9} W_{12}}{1-W_{1} W_{2}-W_{3} W_{5}-W_{3} W_{6} W_{8}-W_{3} W_{6} W_{9} W_{11}} ; \\
W_{F}^{E}=\frac{W_{1} W_{3} W_{6} W_{9} W_{12} W_{15}}{1-W_{1} W_{2}-W_{3} W_{5}-W_{3} W_{6} W_{8}-W_{3} W_{6} W_{9} W_{11}} ; \\
W_{F}^{E}=\frac{W_{3} W_{5}-W_{3} W_{6} W_{8}-W_{3} W_{6} W_{9} W_{11}}{1-W_{1} W_{2}-W_{3} W_{5}-W_{3} W_{6} W_{8}-W_{3} W_{6} W_{9} W_{11}} .
\end{gathered}
$$

Recall that $M(s)=1$ at $s=0$. Because $W_{A}^{E}(s)=p_{A} \cdot M_{A}(s)$, then $p_{A}=W_{A}^{E}(0)$, whence it follows that $M_{A}(s)=\frac{W_{A}^{E}(s)}{p_{A}}=\frac{W_{A}^{E}(s)}{W_{A}^{E}(0)}$. Calculating the $j$-th derivative of the sunction $M_{A}(s)$ and taking $s=0$, it is easy to find the $-j$-th moment $\mu_{j}$ relative to the origin, $\mu_{j}=\left.\frac{\partial^{j} M(s)}{\partial s^{j}}\right|_{s=0}$.

In particular, $\mu_{1}$ relative to the origin is the mathematical expectation of the grid execution time, and the variance of the grid execution time is equal to $D=\sigma^{2}=\mu_{2}-\mu_{1}^{2}$. The value of the standard deviation of the expected completion time of each of the end nodes of the stochastic model makes it possible to determine the appropriate level of risk.

To calculate the parameters of the proposed stochastic model, a software framework was developed in the Statistica system, using which it is possible to study the influence of the values of the output and intermediate data on the final results of the project.

\section{Conclusions}

The involvement of Ukraine in the European Green Deal, the implementation of the National Plan and Waste Management Strategy requires the development and use of innovative materials of a new generation, in particular sulfur polymer. Their application will allow solving environmental and technical and economic problems associated with the utilization of sulfur compounds as a by-product of oil and gas processing.

The purpose of the proposed project is to introduce a systematic approach to creating conditions to stimulate the implementation of strategic directions for the development of the domestic industry for the use of the latest environmental technologies of sulfur polymer materials (sulfur asphalt concrete and sulfur concrete) in the development of the country's infrastructure, providing for the reduction of the ecological, carbon, sulfur-containing and material footprint, the transition to environmentally friendly technological solutions, the 
introduction of the principles of circular economy, while maintaining its competitiveness. A model has been developed to reduce risks and increase the efficiency of the project for the introduction of sulfur polymers in key sectors of the Ukrainian economy.

\section{References}

1. European Commission. (2019). A European Green Deal. https://ec.europa.eu/info/strategy/priorities-2019-2024/european-green-deal en

2. On the Basic Principles (Strategy) of the State Environmental Policy of Ukraine for the period up to 2030. (2019). Law of Ukraine.

3. On approval of the National Strategy for Waste Management in Ukraine until 2030. (2017). Order of the Cabinet of Ministers of Ukraine. No 820-p.

4. Cabinet of Ministers of Ukraine (2019). On approval of the National Waste Management Plan until 2030. Order of the Cabinet of Ministers of Ukraine. No 117-p.

5. Mission of Ukraine to the European Union. (2021). A European Green Deal. https:/ukraine-eu.mfa.gov.ua/posolstvo/galuzeve-spivrobitnictvo/klimat-yevropejskazelena-ugoda

6. Stefanishyna, O. (2021). Ukraine is following the European Green Deal. European Integration portal. https://eu-ua.org/en/news/olga-stefanishyna-ukraine-followingeuropean-green-deal

7. Leonard, M., Pisani-Ferry, J., Shapiro, J., Tagliapietra, S., \& Wolff, G. (2021). The geopolitics of the European Green Deal. https://ecfr.eu/publication/the-geopolitics-ofthe-european-green-deal

8. Andrusevych, A., Andrusevych, N., Khabatiuk, O., Kozak, Z., Kravchuk, V., Movchan, V., Shor K., \& Synytsia, A. (2020). European Green Deal: Opportunities and Threats for Ukraine. Policy Paper. https://www.rac.org.ua/uploads/content/584/files/europeangreen-dealwebfinal.pdf

9. Phillips, D.T., \& Garcia-Diaz, A. (1981). Fundamentals of network analysis. Prentice Hall: Englewood Cliffs.

10. Tymchenko, I.P. (2016). Stochastic modeling of the introduction of methods of analysis of strategic gaps in the enterprise. Innovative Economy, 7-8(64), 155-165.

11. Snityuk, V.V. (2021). Stochastic model of formation of competitive strategies of a dairy enterprise. Scientific research on topical issues of modern economics: materials of the International scientific-practical conference for students, graduate students and young scientists (33-37). Kyiv.

12. Balan, V., \& Kharitonova, L. (2019). Stochastic modeling of the process of selection and implementation of information management system at the enterprise. Efektyvna ekonomika, 4. (In Ukrainian). https://doi.org/10.32702/2307-2105-2019.4.60

13. Vikulova, A.O. (2016). State regulation of commercialization of intellectual property in Ukraine. Extended abstract of Candidate's thesis (Econ. Sciences: 08.00.03). Kyiv, Nat. Univ. Taras Shevchenko of Kyiv.

14. Nelson, R.G., Azaron, A., \& Aref, S. (2016). The use of a GERT based method to model concurrent product development processes. European Journal of Operational Research, 250(2), 566-578. https://doi.org/ 10.1016/j.ejor.2015.09.040

15. European Commission. (2020). Communication from the Commission to the European Parliament, the Council, the European Economic and Social Committee and the Committee of the regions. Sustainable and Smart Mobility Strategy - putting European transport on track for the future. https://ec.europa.eu/transport/sites/transport/files/legislation/com20200789.pdf 